\title{
Emperors on thin ice: three years of breeding failure at Halley Bay
}

\author{
PETER T. FRETWELL and PHILIP N. TRATHAN \\ British Antarctic Survey, NERC, Madingley Road, Cambridge CB3 OET \\ ptf@bas.ac.uk
}

\begin{abstract}
Satellite imagery is used to show that the world's second largest emperor penguin colony, at Halley Bay, has suffered three years of almost total breeding failure. Although, like all emperor colonies, there has been large inter-annual variability in the breeding success at this site, the prolonged period of failure is unprecedented in the historical record. The observed events followed the early breakup of the fast ice in the ice creeks that the birds habitually used for breeding. The initial breakup was associated with a particularly stormy period in September 2015, which corresponded with the strongest El Niño in over 60 years, strong winds, and a record low sea-ice year locally. Conditions have not recovered in the two years since. Meanwhile, during the same three-year period, the nearby Dawson-Lambton colony, $55 \mathrm{~km}$ to the south, has seen a more than tenfold increase in penguin numbers. The authors associate this with immigration from the birds previously breeding at Halley Bay. Studying this 'tale of two cities' provides valuable information relevant to modelling penguin movement under future climate change scenarios.
\end{abstract}

Received 31 October 2018, accepted 1 February 2019

Key words: El Niño, ENSO, emperor penguins, Halley, penguins, sea ice

\section{Introduction}

The emperor penguin (Aptenodytes forsteri Gray) colony at Halley Bay $\left(75^{\circ} 33^{\prime} \mathrm{S}, 27^{\circ} 32^{\prime} \mathrm{W}\right)$ was one of the largest colonies in Antarctica, second only in size to that at Coulman Island in the Ross Sea (Fretwell et al. 2012). The colony is located on the northern side of the Brunt Ice Shelf (Fig. 1) and, for the past two decades, has been situated in a bay, locally named 'Windy Creek'. Although no organized science has been conducted on the colony, it has been visited by staff from the Halley Research Station sporadically from 1956-2012 and estimates of size vary between approximately 14 300-23 000 pairs (Woehler 1993, British Antarctic Survey (BAS) unpublished data, H.J. Gillett personal communication 2018). It is likely that the colony is associated with foraging on the shallow McDonald Bank and McDonald Ice rumples, to the north and east of the site and the coastal polynya that forms north of the Brunt Ice shelf each summer season (Hodgson et al. 2018). Although this polynya is a consistent feature, the sheltered bays bordering the ice shelf usually retain fast ice until December and often the ice remains all summer. This ensures that emperors are able to raise their chicks at the site as their young fledge between mid-December and early January.

Although the recorded population has varied, the colony is consistently the largest in the Weddell Sea, over twice the size of any other colony in the region. There have been no previously recorded instances of total breeding failure at the site. It possibly represents $6.5-8.5 \%$ of the total global population and, as it is situated at high latitudes, it plausibly represents an important climate change refugia (Ainley et al. 2010, Jenouvrier et al. 2017).

The nearest colony to the Halley site is the Dawson-Lambton colony, some $55 \mathrm{~km}$ to the south, located where the Brunt Ice Shelf joins the continental coast (Fig. 1). Geographically this is an unusually small distance between emperor colonies (Ancel et al. 2017). Only the Mertz Ice Shelf colonies have a smaller distance between them, and these two colonies originated from a single site before the recent calving of the Mertz Ice Tongue in 2010 (Ancel et al. 2014).

However, recent monitoring has shown that the Halley Bay colony has suffered catastrophic breeding failure, whilst the nearby Dawson-Lambton colony has markedly increased in size. In this paper very high resolution (VHR) satellite imagery is used to estimate population changes at the two sites over the last ten years.

\section{Methods and materials}

Population size was estimated using VHR satellite images from the WorldView2 and WorldView3 satellites. An identical methodology to that used by Fretwell et al. (2012) was employed. In brief a multivariate supervised classification in ArcGIS (ESRI ${ }^{\circledR A}$ ArcMAPTM 10.4.1) to distinguish the area of penguins in each image from guano, shadows and snow was used. The area of penguins is then converted to a population estimate via a robust-regression analysis using ground truthing from 11 


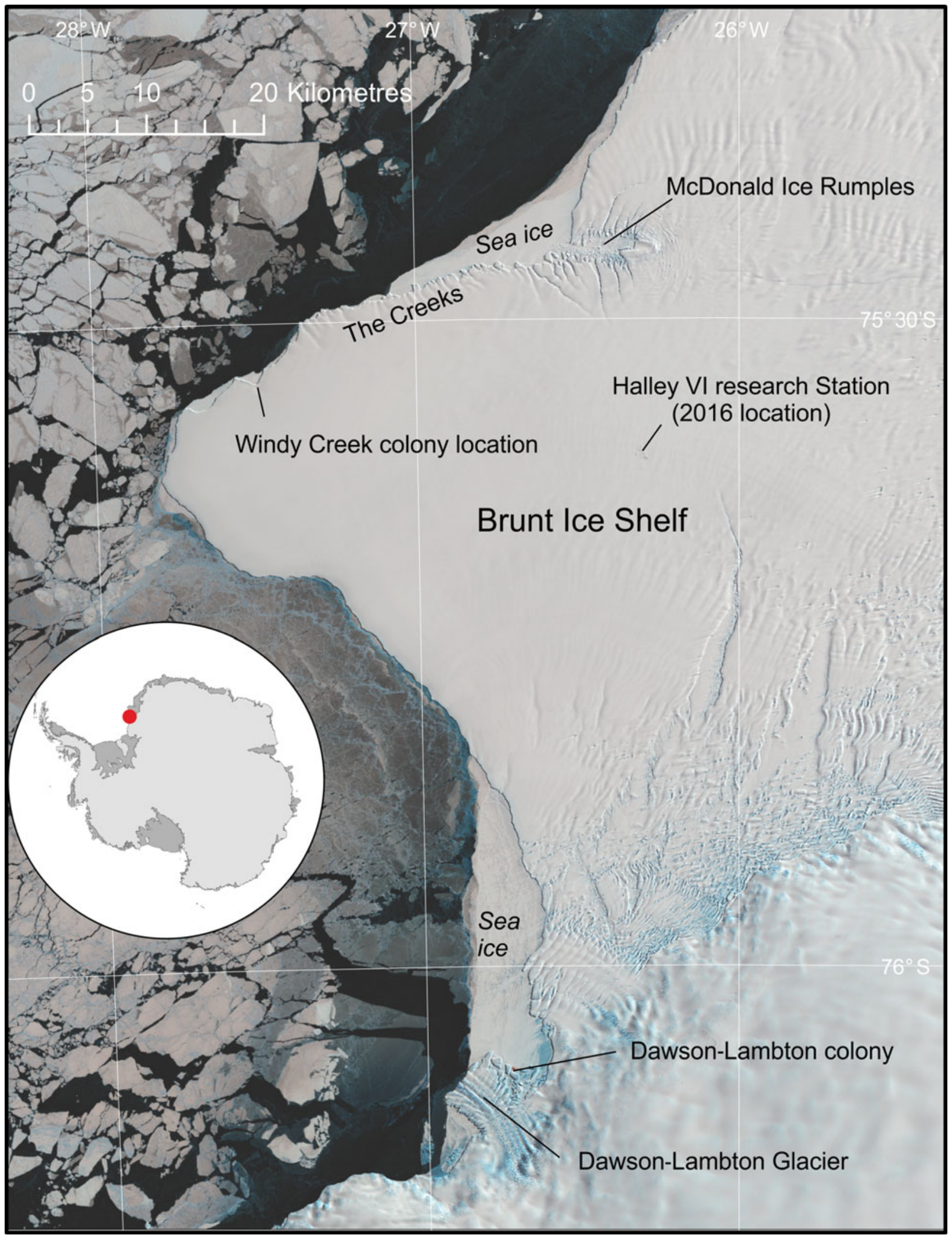

Fig. 1. Overview of the Brunt Ice Shelf, showing the location of Halley Bay and Dawson-Lambton emperor penguin colonies. The underlying image is a Landsat8 image from October 2016. 
sites, which gives an indication of the number of pixels per penguin in the imagery. The variance of each estimate is calculated using a Monte Carlo analysis based upon the image quality and ease of counting of each satellite image. Each estimate refers to the number of penguins at the site at the time of the image acquisition. This includes both adults and chicks. As with Fretwell et al. (2012), the images used were taken during the crèche period of the emperors' breeding cycle; the assumption was made that there will be one adult per breeding pair at the colony site. Although the ratio of adults to chicks changes through the season, the diminishing number of adults is compensated for by the higher visibility of the chicks. In essence, therefore, these counts are comparable to the number of breeding pairs at each site.

VHR satellite imagery, at either $30 \mathrm{~cm}$ or $50 \mathrm{~cm}$ resolution has been collected and analysed at each site, between mid-September and early December every year since 2009 (with the exception of Halley Bay 2016 when all land-fast ice was lost early in the season making analysis irrelevant). This has allowed the construction of a ten-year time sequence of population changes (image details are given in Supplemental material see http://dx. doi.org/10.1017/S0954102019000099). The timing of the imagery coincides with the crèche period of the emperors' breeding cycle and, for all but one image (the Dawson-Lambton image in 2016), is well before the fledging period of the chicks. Due to the variable timing of the imagery a small amount of mortality between earlier imagery and later images would be expected. However, mortality during this period tends to be low (Barber-Meyer et al. 2008) (For a further critique of possible uncertainties, refer to Fretwell et al. 2012).

To supplement the VHR imagery and to give a more complete picture of the sea ice conditions Sentinel2, Sentinel1 and Landsat 8 images have also been assessed.

\section{Results}

\section{Halley Bay}

Satellite imagery over a ten-year period has confirmed considerable variation in colony size (Fig. 2). More importantly, the images have revealed that since 2015 the population has crashed with almost no breeding success in 2016, 2017 and 2018. In 2016 and 2017, low sea ice extent and early breakout of sea ice in spring (October/ November; the crèche period of the emperor's breeding cycle) resulted in complete breeding failure. Satellite observations for this phenomenon were verified by ground observations from staff at the Halley VI research station in November 2016. In 2017 early breakout of fast ice in mid-November confirmed another year of breeding failure (Fig. 2). In 2018 (VHR image date 25 October) the colony reformed, but with only a few hundred adults present at the breeding site $(\sim 2 \%$ of the recent population). Investigation of the local area in the VHR imagery revealed several thousand birds at the sea-ice edge. The exact number is difficult to estimate due to the rough ice surface confusing the automated image analysis. The best estimate is that around five times more birds were at, or within $\sim 100 \mathrm{~m}$ of the sea-ice edge than at the main colony site. Many of the penguins were on refrozen brash ice or newly formed grease ice. This does not include the lines of birds moving between the colony site and the ice edge, which can easily be identified as birds in transit. Emperors do not breed or habitually feed their young at the ice edge as its position is dynamic and the high risk of breakup would pose a danger to unfledged chicks. Whether the adult birds here were failed breeders or non-breeders is difficult to assess from imagery alone. Subsequent Landsat 8 and Sentinel 2 imagery shows that by 29 November 2018, all of the fast ice on the north side of the Brunt Ice Shelf had gone, highlighting a third year of probable total breeding failure. These assumed failed breeding events are of a scale that is not apparent in the long, but sporadic record from the site (H.J. Gillett personal communication 2018, BAS records).

\section{Dawson-Lambton}

Between 2016 and 2018, a massive increase in the numbers of birds at the nearby Dawson-Lambton Glacier colony $\left(76^{\circ} 04^{\prime} \mathrm{S}, 26^{\circ} 40^{\prime} \mathrm{W}\right)$, some $55 \mathrm{~km}$ to the south (Fig. 2) was found. The number of pairs estimated by satellite at this colony had steadily decreased from 3690 pairs in 2010 to 1280 pairs in 2015 . However, numbers suddenly increased to 5315 in 2016, 11117 pairs in 2017 and 14612 pairs in 2018, an increase of over $1000 \%$ from the 2015 estimate (images taken 7 December, 9 December and 25 October respectively, for 2016, 2017 and 2018; for further details on imagery please see supplemental files). The satellite images used to estimate bird numbers showed that, in 2016 and 2017, although breeding birds were evident at Dawson-Lambton, the distribution of birds around the colony was non-typical. Usually breeding birds congregate in loose groups, but in the images from these two years, most birds were widely dispersed over the sea ice, often individually or in groups of less than ten. Many thousands of them were positioned along cracks in the ice and the lack of guano staining in these areas (as opposed to the areas around the more usual breeding location) indicated that they had not been there for long. In 2018, this pattern had changed; there was no loose dispersion of birds and imagery indicated that they had congregated into two distinct groups, with heavy guano staining at each site. One group was in approximately the position occupied over the last five years, but a larger group, approximately 


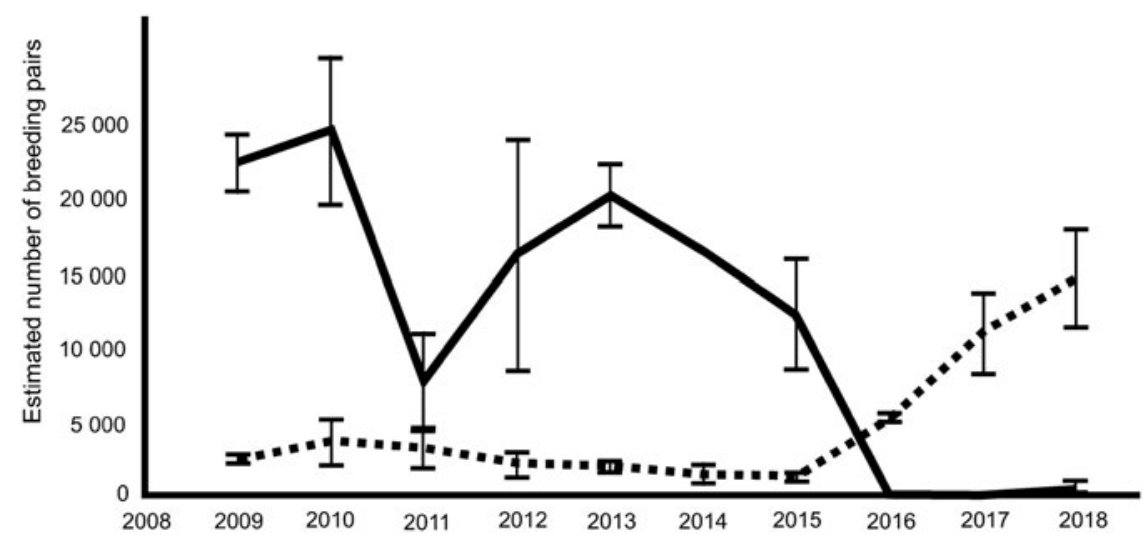

Fig. 2. Variability in the emperor penguin population breeding at Windy Creek, Halley Bay (solid line), and Dawson-Lambton colony (dashed line). Estimates made from very high resolution satellite imagery following the methods of Fretwell et al. (2012); upper and lower $95 \%$ confidence intervals are shown.

2.5 times the size of the other, was in a new site located $1.4 \mathrm{~km}$ to the west.

\section{Discussion}

\section{Dispersion and immigration}

From the loose pattern of birds visible at DawsonLambton in 2017, it is inferred that many of the birds in 2016 and 2017 were not breeding at the site and had possibly arrived later in the season. In 2018, however, the close-huddled groups and heavy guano staining suggest that the majority of the population had been there for some time; this was more consistent with the pattern seen at other breeding colonies.

It appears that many of the birds from Halley Bay have relocated to Dawson-Lambton, with the rest remaining at Halley Bay, but not breeding successfully. This number seems to be diminishing on an annual basis as more failed breeders move to the nearby colony. It is possible that some emperors could have formed a new colony elsewhere, but an exhaustive search using Sentinel2 imagery shows no new colony locations in the region. It is also possible that some birds could have moved to other colony locations further away, but due to the natural variability in colony sizes, small increases in population would be difficult to detect. Another alternative explanation is that some adults have skipped breeding over these years and will return to breed at the original site when conditions there improve. Observations made in the present study emphasize that emperor penguins move between colony sites (LaRue et al. 2015) and, when large colonies move, it can take a number of years for resettlement to occur, similar to the recent situation at the Mertz colony (Ancel et al. 2014).

It is highly likely that the regional population in the Weddell Sea was impacted following the loss of at least three consecutive breeding seasons. Halley comprised a significant proportion of the regional emperor population (on average approximately $23 \%$ of the population of the colonies between $90-0^{\circ} \mathrm{W}$ ) and complete breeding failure in three consecutive seasons will have been important.

\section{Environmental drivers}

The breeding failure and reasons for relocation are almost certainly linked to the early breakup of sea ice at the Halley Bay site (Barbraud \& Weimerskirch 2001, Barbraud et al. 2011), but exactly why that breakup occurred is unknown. It is interesting that the first year of poor sea-ice conditions immediately followed the strongest El Niño in over 60 years, one of the most positive values of the Southern Annular Mode (SAM) and a record low sea-ice year for Halley Bay. (Ocean Niño Index (ONI) data available from https:// climatedataguide.ucar.edu/climate-data/nino-sst-indicesnino-12-3-34-4-oni-and-tni) (see supplemental Fig. 1 at http://dx.doi.org/10.1017/S0954102019000099, data available from https://legacy.bas.ac.uk/met/READER/ surface/stationpt.html; SAM data available from http:// www.nerc-bas.ac.uk/icd/gjma/sam.html). However, without a longer time series of population data and sea-ice records, it is impossible to ascertain whether similar population declines have followed previous years with strong ONI or SAM signals. A long time series would also be required to ascertain whether the origin of the colony at Halley Bay followed similar events elsewhere that led to colony failure and resettlement over longer time periods than the historical record.

What is certain is that in September 2016 just prior to the satellite image shown in Fig. 2b, average atmospheric pressure for the month was the lowest for September in over 30 years, whilst average wind speed was the highest in September over a similar time frame. Temperatures were also higher than average. Wind speeds at Halley 

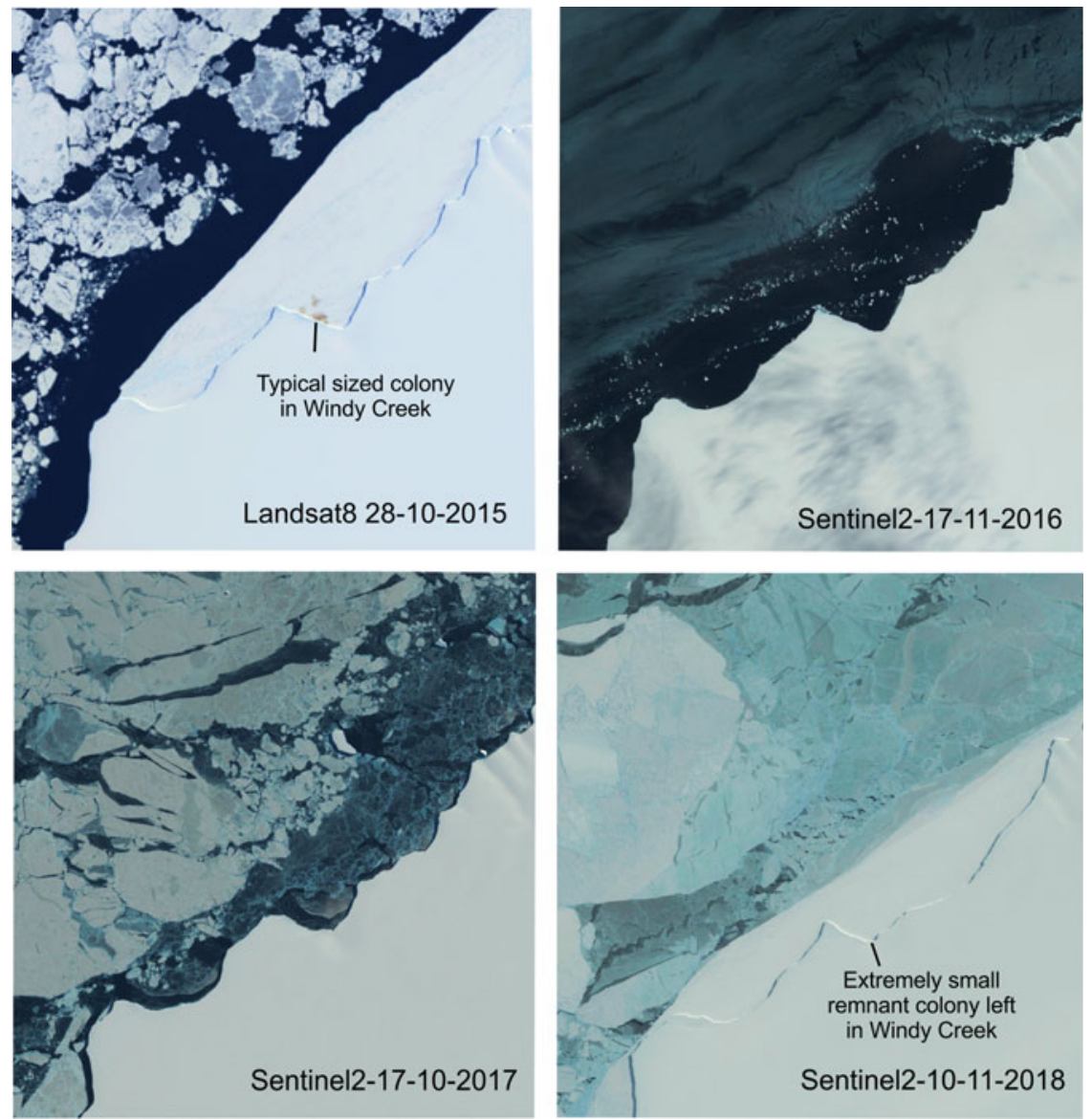

Fig. 3. Medium resolution satellite imagery of the Windy Creek breeding site for the years between spring 2015 and spring 2018.

tend to be strongest during August, September and October (Turner et al. 2009), and the timing of strong wind events in relation to key aspects of breeding will almost certainly be important.

Understanding how environmental drivers, such as changes in SAM, sea ice, or wind speed, direction and velocity, impact upon the breeding colony at Halley, or indeed elsewhere, remains a key challenge. Further, exploring how extremes of such events lead to breeding failure is vital for projecting future population trajectories in a warming environment. The relationship between climate change and El Niño events, or positive SAM anomalies is still a matter of active research (Trenberth \& Hoar 1997, Turner 2004, Turner et al. 2005, Yeh et al. 2009, Collins et al. 2010, Bracegirdle 2013, Cai et al. 2015). Recent research suggests that the frequency of El Niño and La Niña events are predicted to increase, while ENSO-related catastrophic weather events are also likely to occur more frequently with unabated greenhouse gas emissions (Cai et al. 2015). However, other evidence cautions that it is not yet possible to say whether ENSO activity will be enhanced or damped, or if the frequency of events will change (Collins et al. 2010). The evidence from observations of the present authors, and from earlier papers (Kooyman et al. 2007, Ancel et al. 2014), points to the fact that stochastic impacts upon emperors may be vital, even for high-latitude locations. Strong winds, or storm events can create coastal leads or polynyas that are beneficial to foraging, but prolonged periods of extreme winds can also lead to breakup and dissipation of fast ice, which can cause total breeding failure when it occurs at a sensitive time for the penguins.

At Halley, another important factor influencing the stability of the fast ice around the colony could be the dynamic nature of the creek in which it is located. Until recently, the colony was situated within a sheltered ice creek, on the northern side of the Brunt Ice Shelf, informally named Windy Creek. Over the past 60 years, the colony has occasionally moved to other adjacent sheltered creeks (H.J. Gillett personal communication 2018, BAS records). With the fast-ice breakout in 2016, ice shelf morphology changed (Fig. 3) and the resulting more open nature of the creek may now be less suitable for fast-ice retention. The Brunt Ice Shelf is a fast-moving and dynamic environment (Hodgson et al. 2018). Over the last two decades the creek has gradually moved westwards by over $600 \mathrm{~m}$ per year and it is possible that 
the migration and changing topography of Windy Creek has made it a less favourable site for emperor penguins. Any future breeding at Halley will almost certainly depend upon the juxtaposition of sheltered, stable fast ice, foraging opportunities, including over the nearby McDonald Bank, and the longer-term processes that will happen once the Brunt Ice Shelf calves, which at present rates will be within the next two years.

\section{Conclusion}

The authors describe an unprecedented three-year period of breeding failure at the large Halley Bay emperor penguin colony. They link this to a dramatic rise in the population of the nearby Dawson-Lambton colony, a rise that can only have occurred due to immigration from Halley. These changes have been driven by a change in sea-ice conditions and early breakup of fast ice on the northern side of the Brunt Ice Shelf, which may be due to ENSO events and/or ice-shelf morphology.

In a warming world, it will be crucial to better understand the interplay between wind and ice shelf orography, and to appreciate how these factors impact the location of emperor penguin colonies. Understanding how emperor penguins react to catastrophic sea-ice loss will be of crucial importance if one is to predict the fate of the species over coming decades.

\section{Acknowledgements}

WWF-UK supported the project under Grant GB095701. The authors are grateful to Jennifer Brown for assistance with image processing and Louise Ireland for ordering imagery. The authors are also grateful to Michelle La Rue and Barbara Wienecke for helpful comments on an earlier draft of this manuscript.

\section{Author contribution}

PTF oversaw the analysis of remote sensing imagery. PNT and PTF designed the study and wrote the paper.

\section{Supplemental material}

Supplemental satellite image data and supplemental Fig. S1 will be found at http://dx.doi.org/10.1017/ S0954102019000099.

\section{References}

Ainley, D., Russell, J., Jenouvrier, S., Woehler, E., Lyver, P.O., Fraser, W.R. \& Kooyman, G.L. 2010. Antarctic penguin response to habitat change as Earth's troposphere reaches $2^{\circ} \mathrm{C}$ above preindustrial levels. Ecological Monographs 80, 10.1890/08-2289.1.

Ancel, A., Cristofari, R., Fretwell, P.T., Trathan, P.N., Wienecke, B., Boureau, M., et al. 2014. Emperors in hiding: when ice-breakers and satellites complement each other in Antarctic exploration. PLoS One, 9, 10.1371/journal.pone.0100404.

Ancel, A., Cristofari, R., Trathan, P.N., Gilbert, C., Fretwell, P.T. \& Beaulieu, M. 2017. Looking for new emperor penguin colonies? Filling the gaps. Global Ecology and Conservation, 9, 10.1016/ j.gecco.2017.01.003

Barber-Meyer, S.M., Kooyman, G.L. \& Ponganis, P.J. 2008. Trends in western Ross Sea emperor penguin chick abundances and their relationship with climate. Antarctic Science, 20, 3-11.

Barbraud, C. \& Weimerskirch, H. 2001. Emperor penguins and climate change. Nature, 411, 183.

Barbraud, C., Gavrilo, M., Mizin, Y. \& Weimerskirch, H. 2011. Comparison of emperor penguin declines between Pointe Géologie and Haswell Island over the past 50 years. Antarctic Science, 23, $10.1017 /$ S0954102011000356.

BRACEgIRDLE, T.J. 2013. Climatology and recent increase of westerly winds over the Amundsen Sea derived from six reanalyses. International Journal of Climatology, 33, 10.1002/joc.3473.

CaI, W., Santoso, A., Wang, G., Yeh, S.-W., An, S.-I., Сobb, K.M., et al. 2015. ENSO and greenhouse warming. Nature Climate Change, 5, 10.1038/NCLIMATE2743.

Collins, M., An, S.-I., CaI, W., Ganachaud, A., Guilyardi, E., Jin, F.-F., et al. 2010. The impact of global warming on the tropical Pacific Ocean and El Niño. Nature Geoscience, 3, 10.1038/ngeo868.

Hodgson, D.A., Hogan, K., Smith, J.M., Smith, J.A., Hillenbrand, C.-D., Graham, A.G.C., et al. 2018. Deglaciation and future stability of the Coats Land ice margin, Antarctica. The Cryosphere, 12, 10.5194/ tc-12-2383-2018.

Fretwell, P.T., LaRue, M.A., Morin, P., Kooyman, G., Wienecke, B., Ratcliffe, N., et al. 2012. An emperor penguin population estimate: the first global, synoptic survey of a species from space. PLoS One 7, e33751.

Kooyman, G.L., Ainley, D.G., Ballard, G. \& Ponganis, P.J. 2007. Effects of giant icebergs on two emperor penguin colonies in the Ross Sea, Antarctica. Antarctic Science, 19, 31-38.

Jenourviter, S., Garnier, J., Patout, F. \& Desvilletters, L. 2017. Influence of dispersal processes on the global dynamics of emperor penguin, a species threatened by climate change. Biological Conservation, 212, 10.1016/j.biocon.2017.05.017.

LaRue, M.A., Kooyman, G., Lynch, H.J. \& Fretwell, P.T. 2015. Emigration in emperor penguins: implications for interpretation of long-term studies. Ecography, 38, 10.1111/ecog.00990.

Trenberth, K.E. \& Hoar, T.J. 1997. El Niño and climate change. Geophysical Research Letters, 24, 3057-3060.

Turner, J. 2004. The El Niño-southern oscillation and Antarctica. International Journal of Climatology, 24, 10.1002/joc. 965.

Turner, J., Colwell, S.R., Marshall, G.J., Lachlan-Cope, T.A., Carleton, A.M., Jones, P.D., et al. 2005. Antarctic climate change during the last 50 years. International Journal of Climatology, 25, 10.1002/joc. 1130 .

Turner, J., Chenoli, S.N., Abu Samah, A., Marshall, G., Phillits, T. \& OrR, A. 2009. Strong wind events in the Antarctic. Journal of Geophysical Research - Atmospheres, 114, 10.1029/2008JD011642.

Woehler, E.J. \& Poncet, S. 1993. The distribution and abundance of Antarctic and Subantarctic penguins. Cambridge: Scientific Committee on Antarctic Research, 76 pp.

Yeh, S.-W., Kug, J.-S., Dewitte, B., Kwon, M.-H., Kirtman, B.P. \& JIN, F.-F. 2009. El Niño in a changing climate. Nature, 461, 10.1038/ nature 08316. 